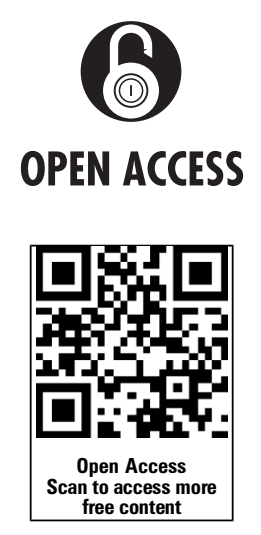

- Additional material is published online only. To view please visit the journal online (http://dx.doi.org/10.1136/ gutjnl-2013-306453).

For numbered affiliations see end of article.

\section{Correspondence to} Else-Mariette van Heijningen, Department of Public Health, Erasmus MC University Medical Centre, P.0. Box 2040, Rotterdam 3000 CA, the Netherlands; e.vanheijningen@erasmusmc.nl

Received 16 November 2013 Revised 29 September 2014 Accepted 18 October 2014 Published Online First 13 January 2015
CrossMark

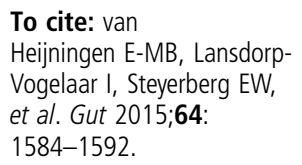

\title{
Adherence to surveillance guidelines after removal of colorectal adenomas: a large, community-based study
}

\author{
Else-Mariëtte B van Heijningen, ${ }^{1}$ Iris Lansdorp-Vogelaar, ${ }^{1}$ Ewout W Steyerberg, ${ }^{1}$ \\ S Lucas Goede, ${ }^{1}$ Evelien Dekker, ${ }^{2}$ Wilco Lesterhuis, ${ }^{3,4}$ Frank ter Borg ${ }_{1}{ }^{5}$ Juda Vecht, ${ }^{6}$ \\ Pieter Spoelstra, ${ }^{7}$ Leopold Engels, ${ }^{8}$ Clemens J M Bolwerk, ${ }^{9}$ Robin Timmer, ${ }_{1}^{10}$ \\ Jan H Kleibeuker, ${ }^{11}$ Jan J Koornstra, ${ }^{11}$ Harry J de Koning, ${ }^{1}$ Ernst J Kuipers, ${ }^{3,12}$ \\ Marjolein van Ballegooijen ${ }^{1}$
}

\section{ABSTRACT}

Objective To determine adherence to recommended surveillance intervals in clinical practice.

Design 2997 successive patients with a first adenoma diagnosis ( $57 \%$ male, mean age 59 years) from 10 hospitals, who underwent colonoscopy between 1998 and 2002, were identified via Pathologisch Anatomisch Landelijk Geautomatiseerd Archief: Dutch Pathology Registry. Their medical records were reviewed until 1 December 2008. Time to and findings at first surveillance colonoscopy were assessed. A surveillance colonoscopy occurring within \pm 3 months of a 1-year recommended interval and \pm 6 months of a recommended interval of 2 years or longer was considered appropriate. The analysis was stratified by period per change in guideline (before 2002: 2-3 years for patients with 1 adenoma, annually otherwise; in 2002: 6 years for 1-2 adenomas, 3 years otherwise). We also assessed differences in adenoma and colorectal cancer recurrence rates by surveillance timing.

Results Surveillance was inappropriate in $76 \%$ and $89 \%$ of patients diagnosed before 2002 and in 2002, respectively. Patients eligible under the pre-2002 guideline mainly received surveillance too late or were absent (57\% of cases). For patients eligible under the 2002 guideline surveillance occurred mainly too early $(48 \%)$. The rate of advanced neoplasia at surveillance was higher in patients with delayed surveillance compared with those with too early or appropriate timed surveillance ( $8 \%$ vs $4-5 \%, p<0.01$ ).

Conclusions There is much room for improving surveillance practice. Less than $25 \%$ of patients with adenoma receive appropriate surveillance. Such practice seriously hampers the effectiveness and efficiency of surveillance, as too early surveillance poses a considerable burden on available resources while delayed surveillance is associated with an increased rate of advanced adenoma and especially colorectal cancer.

\section{INTRODUCTION}

Colorectal cancer (CRC) is one of the leading causes of cancer-related death in the Western world. $^{1}{ }^{2}$ Individuals with adenomas are at increased risk to develop CRC compared with the

\section{Significance of this study}

What is already known on this subject?

- A considerable proportion of colonoscopy use concerns procedures for surveillance purposes. This proportion will further increase with the introduction of mass screening for colorectal cancer (CRC).

- For optimal effectiveness of CRC prevention and limitation of resource depletion, adherence to postpolypectomy surveillance guidelines is mandatory.

- Surveys show that gastroenterologists often advise shorter surveillance intervals than recommended by guidelines.

- No large studies have assessed adherence to surveillance guidelines in clinical practice.

What are the new findings?

- In clinical practice, only a minority of patients (11-24\%) receives appropriate surveillance according to guidelines. This is considerably lower than previously estimated from surveys.

- Over $45 \%$ of patients receive too intense surveillance compared with the 2002 guidelines.

- Compared with appropriate or too early surveillance, delayed surveillance was associated with a higher rate of advanced and nonadvanced neoplasia at surveillance colonoscopy.

- Poor penetration of the 2002 surveillance guidelines within 1 year following implementation illustrates the importance of convincing evidence to support endorsement of new guidelines by physicians.

How might it impact on clinical practice in the foreseeable future?

- Physicians should realise that current adherence to guidelines is inappropriate and that that can seriously hamper effectiveness and efficiency of surveillance.

- Specific interventions should be compared for their effectiveness to improve guideline adherence. 
average population, even after the adenoma has been removed. $^{3-6}$ Patients with adenoma are therefore recommended to undergo regular colonoscopy surveillance. ${ }^{7-10}$ Currently in the USA about $15-25 \%$ of all colonoscopy procedures are being performed for surveillance purposes, ${ }^{11}{ }^{12}$ while in the Netherlands estimates range from $13 \%$ to $40 \%{ }^{13}{ }^{14}$ Previous research indicated that adherence to postpolypectomy surveillance guidelines is insufficient. ${ }^{15-23}$ While too little surveillance threatens the effectiveness of CRC prevention, too intensive surveillance may lead to unnecessary harms and makes inefficient use of colonoscopy resources.

The introduction of mass screening for CRC combined with aging of the population in many Western countries will considerably increase the number of patients with adenoma in the coming years, and thus the number of surveillance colonoscopies required. The number of colonoscopies in the Netherlands has increased significantly from 117000 in 2004 to 191000 in $2009 .{ }^{24}$ An additional $66000-99000$ colonoscopies each year are expected with full implementation of CRC screening (after a positive faecal immunochemical blood test plus subsequent surveillance). ${ }^{1325} 26$ The associated increase in colonoscopy demand together with the limited colonoscopy capacity in many countries ${ }^{27-30}$ emphasise the importance of efficiency in surveillance practice and therefore adherence to surveillance guidelines.

Previous studies regarding adherence to postpolypectomy surveillance guidelines mainly consisted of surveys among gastroenterologists, in which the follow-up decision of the gastroenterologist was compared with the guidelines' recommendation. ${ }^{16} 1820{ }^{31}$ However the gastroenterologist's intention immediately after the index colonoscopy is only one factor on whether and when surveillance colonoscopy will take place. Moreover these studies may be prone to bias because of medically desirable answers. Few studies assessed actual adherence to postpolypectomy surveillance guidelines. ${ }^{19} 23 \quad 32$ These were either relatively small single-centre studies ${ }^{19} 3233$ or based on a self-reported patient survey. ${ }^{23}$ In addition, the proportion of patients not having surveillance at all was not always assessed.

We aimed to determine the extent of adherence to postpolypectomy surveillance guidelines in community-based clinical practice, in which we were also in the position to assess the influence of a change in guideline on adherence rates.

\section{METHODS}

\section{Patient selection}

We used the nationwide registry of histopathology and cytopathology in the Netherlands (Pathologisch Anatomisch Landelijk Geautomatiseerd Archief, PALGA) ${ }^{34}$ to identify patients with a first adenoma diagnosis in the period from 1 June 1998 to 31 December 2002 in 10 hospitals (3 academic and 7 non-academic) throughout the Netherlands. This registry includes a résumé of findings of all tissue materials (eg, polyps, biopsies) that have been submitted at any pathology centre in the Netherlands since 1991. Years of inclusion of patients with adenoma per hospital depended on the availability of electronic medical records. Patients with a first adenoma diagnosis aged 4074 years were eligible for inclusion. Patients with any of the following criteria were excluded: (1) (suspected) hereditary CRC syndromes, in particular Lynch syndrome (hereditary nonpolyposis colorectal carcinoma), familial adenomatous polyposis, Peutz-Jeghers syndrome, juvenile polyposis or polyposis associated with mutations in the MUTYH gene; (2) personal history of CRC or CRC at index colonoscopy; (3) (previous) bowel resections; (4) IBD; (5) acromegaly; (6) ureterosigmoidostomy; and (7) recommended age of next surveillance exceeded the recommended age to stop surveillance. Exclusion criteria 4 to 6 are associated with an increased CRC risk, and we have therefore excluded patients with these conditions.

\section{Data collection}

After identification of patients with a first adenoma diagnosis via the PALGA database, patients' medical records, in particular endoscopy and pathology reports, were reviewed in 10 hospitals to collect information on patient characteristics, index and surveillance colonoscopy (colonoscopy or sigmoidoscopy) including corresponding adenoma characteristics, until 1 December 2008, the end of the study. Index colonoscopy was defined as colonoscopy or sigmoidoscopy with first adenoma diagnosis. We considered repeat colonoscopy examinations performed either within 6 months after index colonoscopy, or after surveillance colonoscopy as one examination. In case of combining results from colonoscopies, the date of last colonoscopy with the fullest reach including polypectomy was used. For all patients, date of index colonoscopy, age and sex were collected. In patients without a surveillance colonoscopy before 1 December 2008, we only collected data on index colonoscopy characteristics and adenoma findings in a randomly picked sample of 40\% (433/1093) of patients. In all patients with surveillance after adenoma detection we collected data on colonoscopy characteristics and adenoma findings, at index and surveillance colonoscopy.

This study was approved by the Institutional Review Board of Erasmus MC University Medical Centre and all participating centres.

\section{Outcomes}

We evaluated the time interval to first surveillance colonoscopy as our main outcome measure. Absence of surveillance was defined as not having received surveillance within 90 months or before the end of the study period, whichever came first. The definition of appropriate surveillance was based on the active guideline. In the Netherlands, from June 1998 to October 2001, patients with one adenoma were recommended a 2-3 year surveillance interval; patients with more than one adenoma a 1 -year interval. ${ }^{35} 36$ In October 2001, a revised guideline was published and implemented from January 2002 onwards. It was communicated at a national conference and through a report including a wallet sized card with the summary of the guideline by the Dutch Institute for Healthcare Improvement. ${ }^{37}$ The revised guideline recommended patients with three or more adenomas to have surveillance after 3 years, and patients with fewer than three adenomas to return for surveillance after 6 years. Surveillance colonoscopy could be ceased after age 65 years for patients with cumulative one adenoma at that age, and after age 75 years for patients with cumulative two adenomas. ${ }^{10}$ The timing of surveillance colonoscopy was arbitrarily considered appropriate if surveillance has been performed within the range of \pm 3 months for the 1-year recommendation, and \pm 6 months for the 2-6 year recommendations. The corresponding appropriate surveillance intervals are given in table 1 . We also assessed the yield of advanced adenoma (AA) and non-AA at surveillance colonoscopy and relate this to the number of adenomas at index colonoscopy and surveillance interval.

\section{Statistical analysis}

We used Kaplan-Meier (KM) analysis to estimate the probability over time since polypectomy that a patient would have surveillance colonoscopy. The analysis was stratified by two different periods corresponding to the active guideline (June 1998 to 2002, and from 2002 onwards), and by adenoma number at 
Table 1 Recommended surveillance intervals and intervals considered appropriate in the presented analysis

\begin{tabular}{llll}
\hline & Adenoma findings at index colonoscopy & Surveillance interval recommendation & Interval considered appropriate* $^{*}$ \\
\hline June 1998-2001 & $\geq 2$ adenomas & 12 months (1 year) & $9-15$ months \\
Since 2002 & 1 adenoma & $24-36$ months (2-3 years) & $18-42$ months \\
& $\geq 3$ adenomas & 36 months (3 years) & $30-42$ months \\
\hline
\end{tabular}

${ }^{*}$ Appropriate interval is \pm 3 months for a 1 -year interval recommendation and \pm 6 months for longer interval recommendations.

index colonoscopy: one, two, and three+ adenomas. Each patient in the study cohort was followed from index colonoscopy until the first surveillance colonoscopy, or until censored. Patients were censored (A) at reported time of death, (B) on 1 December 12008 or (C) 90 months after index colonoscopy, whichever came first. We assumed no loss to follow-up.

Differences in characteristics between groups were assessed by the Mann-Whitney U test, Kruskal-Wallis test or $\chi^{2}$ test. The log-rank test (Mantel-Cox) was used to compare KM curves. All statistical analyses were conducted using the Statistical Package for Social Sciences for Windows V.17.0 (SPSS, Chicago, Illinois, USA). Two-sided $\mathrm{p}$ values $<0.05$ were considered statistically significant.

\section{Missing values}

To perform the KM analysis stratified by active guideline and adenoma number at index colonoscopy, we needed data on adenoma number for all subjects. However, we only collected data on adenoma findings for a subgroup of patients without surveillance $(n=433 / 1093)$. For missing values for adenoma number $(n=660)$ and gender $(n=1)$ we used a statistical imputation technique. ${ }^{38}$ Imputations were based on correlations with patient characteristics (age and sex); hospital type (academic or non-academic); year of index colonoscopy, reach and preparation of index colonoscopy; adenoma characteristics (number of adenomas; presence of villous adenoma; presence of adenomas sized $\geq 10 \mathrm{~mm}$ (as measured by the endoscopist or pathologist); adenomas with high-grade dysplasia; and proximal adenomas); and presence of a surveillance colonoscopy, using the aregImpute function in R V.2.11 software ( $\mathrm{R}$ foundation for statistical computing, Vienna, Austria).

\section{Subanalyses}

To assess the influence of having hospitals in the data set without observations over the whole index period (June 19982002), we compared the KM curves of surveillance timing from five hospitals with data over the whole period with the other hospitals.

Also, two subanalyses were performed regarding implementation issues. A change in guideline usually involves a transitional phase in which anticipation (before) and implementation issues (after) influence actual practice. Regarding the former issue, endoscopists possibly anticipated the lengthening of the surveillance intervals in upcoming guidelines. Also, because of the change in the guideline in 2002, clinicians may have prolonged surveillance intervals for patients with a first adenoma diagnosis in 2001 retroactively. We therefore considered the period from October 2000 (1 year before guideline publication) until December 2001 as the transitional phase between the two guidelines. We compared the median surveillance intervals and results of the KM analysis between the periods June 1998October 2000 and October 2000-December 2001.

Second, because it might take time to familiarise and comply with a new guideline, we also compared median surveillance intervals and the results of the KM analysis for the first half of 2002 versus the second half of 2002 .
Additionally, we compared KM curves of time to surveillance colonoscopy between academic and non-academic hospitals and between hospitals with or without an active follow-up system. In general, gastroenterologists gave surveillance recommendations to their patients and informed the patients' general practitioner. In hospitals with an active follow-up system patients were actively reminded to have surveillance colonoscopy by the endoscopy centre. For all subanalyses we looked at patients with one, two or three + adenomas separately.

\section{RESULTS}

A total of 2997 patients with a first adenoma diagnosis were included in our study (figure 1). Their mean age was 58.6 (SD 9.0) years and $57.2 \%$ were male (table 2 ). Of all index endoscopies, $2691(89.8 \%)$ were intended colonoscopies and 306 $(10.2 \%)$ were sigmoidoscopies. In total, 2303 patients had a first adenoma diagnosis before 2002 and 694 patients in 2002. Most patients with adenoma $(70 \%)$ were seen in non-academic hospitals. Of all patients with adenoma $11.6 \%$ had three or more adenomas. The contribution to this study in the number of patients per hospital varied from 84 to 565 .

The study follow-up period considered in our analysis for patients diagnosed before 2002 ranged between 83 months and 90 months. For the patients diagnosed in 2002 it was between 71 months and 82 months. Of the patients with surveillance colonoscopy, the median (25th-75th centile) intervals to first surveillance colonoscopy were 25 (13-40) months for patients with their index colonoscopy before 2002 and 35 (14-48) months for those with their index colonoscopy in $2002(\mathrm{p}<0.001)$. Before 2002, median surveillance intervals were 27 (13-45) months for those with one adenoma, 22 (12-37) months for those with two adenomas and $16(12-35)$ months for patients with three+ adenomas $(p<0.001)$. In 2002, these intervals were 37 (20-50) months for those with one adenoma, 35 (13$45)$ months for those with two adenomas and 24 (1237) months for patients with three+ adenomas $(p<0.001)$.

Patients with an index colonoscopy in 2002 were seen after a longer interval than those with an index colonoscopy before 2002 (figure 2A-C). Overall, 21\% of patients with adenoma received appropriate surveillance (table 3 ). The pre-2002 surveillance guideline was better adhered to than the 2002 guideline (24\% vs $11 \%$ appropriateness). In both periods, a higher proportion of patients with three + adenomas received appropriate surveillance than patients with one and two adenomas (before 2002: $30 \%$ vs $24 \%$ and $23 \%$, and in 2002: $18 \%$ vs $9 \%$ and $11 \%$, respectively).

The overall yield of AA at surveillance was 5\% and 7\% for patients in both index periods, respectively (table 4). The yield of non-AA was $22 \%$ for both periods (see online supplementary appendix 1). The yield of AA at surveillance was, in particular in the index period before 2002, higher in patients with delayed surveillance compared with those with too early or appropriate timed surveillance $(8 \%$ vs $3 \%$ and $4 \%, \mathrm{p}<0.01)$. This also pertained to the yield of CRC $(1.8 \%$ vs $0.2 \%$ and $0.4 \%, \mathrm{p}<0.01)$. 
Figure 1 Identification of the study cohort and the subgroups.

6154 persons with first adenoma diagnosis ( $\geq 40$ years) identified via the nationwide histopathology archive (Pathologisch Anatomisch Landelijk Geautomatiseerd Archief, PALGA) (June 1998 - 2002)

1770 patients excluded for one or more reasons after linkage with hospital medical records

4384 adenoma patients ( $\geq 40$ years at index colonoscopy)

905 adenoma patients aged $\geq 75$ years at index colonoscopy

3479 adenoma patients aged $40-74$ years in the cohort

482 adenoma patients were eligible to stop surveillance according to the 2002 guideline

2997 eligible adenoma patients aged $40-74$ years in the cohort

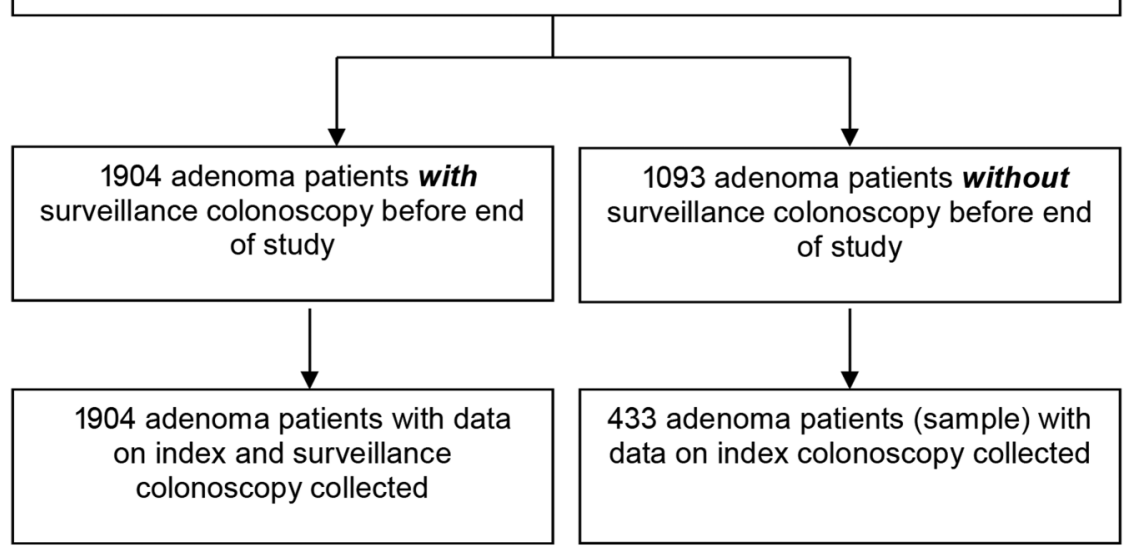

\section{Subanalyses}

Results of all subanalyses are presented in online supplementary appendix 2. No differences were observed in surveillance pattern when comparing five hospitals with data over the whole index period (1998-2002) with those without.

Patients with an index colonoscopy in the phase immediately preceding the change in guideline (October 2000-December 2001) had a significantly longer median ( 25 th- 75 th centile) surveillance interval than patients with an index colonoscopy between June 1998 and October 2000: 29 (14-44) months versus $21(12-39)$ months $(\mathrm{p}<0.001)$. However, KM curves for these two periods were only significantly different for patients with one adenoma $(\mathrm{p}<0.001)$.

Median surveillance intervals were similar between patients with an index colonoscopy in the first half of 2002 versus those in the second half of 2002 for patients with one, two or three+ adenomas (data not shown). Also, KM curves did not differ significantly, indicating no significant implementation issues concerning the new guideline, although the period might have been too short.

When comparing surveillance pattern from academic versus non-academic hospitals, a difference was observed for patients with one or two adenomas with their index colonoscopy before 2002, with longer intervals and less follow-up in academic centres. For hospitals with an active versus passive follow-up system, a different surveillance pattern was observed in patients with two or more adenomas in 2002, with longer intervals and less follow-up in centres with an active follow-up system.

\section{DISCUSSION}

This study shows high proportions of inappropriate adherence to the postpolypectomy surveillance guidelines that are in effect in the Netherlands. This finding holds for both guideline periods considered: before 2002 , only $24 \%$ of patients received appropriately timed adenoma-surveillance; in 2002 only $11 \%$ did. Overall, a third of the patients did not receive surveillance at all by the end of the study period. The absence of surveillance in such a large fraction of the patients is alarming, because advanced neoplasia was found in $8 \%$ (of which a fifth were CRCs) of those with delayed surveillance, and in particular up to $17 \%$ in those with three or more adenomas at index colonoscopy.

Before 2002, inappropriate surveillance was predominantly too late or absent (together, $57 \%$ of patients), while in 2002, when the recommended surveillance intervals were lengthened, 
Table 2 Characteristics of the study population at index colonoscopy $(n=2997)$

All patients $(n=2997)$

\section{Characteristics of patients with adenoma}

Male (n, \%)

$1713(57.2)$

Age (mean, SD)

$58.6(9.0)$

Active guideline $(n, \%)$

June 1998-2001

$2303(76.8)$

2002

$694(23.2)$

Hospital type $(n, \%)$

Non-academic

$2097(70.0)$

Academic

$900(30.0)$

Geographical area $(n, \%)$

High density population area $\quad 1641$ (54.8)

Low density population area $\quad 1356(45.2)$

Active follow-up system ( $\mathrm{n}, \%)$

No

$1975(65.9)$

Yes

$1022(34.1)$

Adenoma characteristics

No. of adenomas (mean, SD)*

$1.5(0.9)$

No. patients with $(\mathrm{n}, \%)$

multiple $(\geq 3)$ adenomas*

347 (11.6)

Any adenoma with size $\geq 10 \mathrm{~mm} \dagger$

$1127(37.6)$

Any adenoma with high-grade dysplasiat

$368(12.3)$

Any villous adenomat

$150(5.0)$

Any proximal adenomat

$900(30.0)$

Index endoscopy characteristics

Intended sigmoidoscopy $(\mathrm{n}, \%)$

$306(10.2)$

Reach endoscope $(n, \%) \dagger$

Complete colonoscopy§

$2538(84.7)$

Proximal colon

293 (9.8)

Distal colon

$166(5.5)$

Bowel preparation $(\mathrm{n}, \%) \dagger$

Goodๆ

2723 (90.9)

Moderate

Insufficient

$52(1.7)$

*Variable truncated to 5+ adenomas, and imputed for missing values. tWeighted average (data from 433 patients without surveillance weighted to the 1093 patients without surveillance).

¥Size $\geq 10 \mathrm{~mm}$ either as reported by an endoscopist or a pathologist.

$\S 58$ missings assumed to have a complete colonoscopy (in $2337(1904+433)$ patients with data).

१1598 missings assumed to have a good bowel preparation (in $2337(1904+433)$

patients with data).

$48 \%$ of the patients received surveillance too early. Appropriate adherence to surveillance guidelines was somewhat higher for patients with three or more adenomas than for patients with fewer than three adenomas (overall, $26 \%$ vs $21 \%$ ).

The fact that surveillance was mostly delayed before 2002 can be expected when the recommended intervals are relatively short (1 year and 2-3 years). This finding coincides with the findings of two previous small single-centre studies from the Netherlands and the UK. ${ }^{19}{ }^{39}$ The 2002 change in recommendations to 3 years for patients with three+ adenomas and 6 years for patients with one to two adenomas was associated with a change in average practice towards longer surveillance intervals. However, the increase in interval in actual practice was smaller than the increase in the guideline-recommended interval. As a result, the proportion of patients that received too early surveillance increased from $19 \%$ before 2002 to $48 \%$ in 2002. This proportion was higher for patients with one to two adenomas compared with those with three+ adenomas $(50 \%$ vs
$39 \%$ in 2002). The impact of too early surveillance on colonoscopy demand will be largest in patients with one to two adenomas, since this group represents more than $80 \%$ of the current patient population with adenoma.

The poor penetration of the 2002 guideline within 1 year following the implementation illustrates the importance of convincing evidence to support endorsement of new guidelines by community practice. The 2002 guideline was formulated when only limited data were available and showed differences with other international guidelines. It has also been shown that gastroenterologist experienced dilemmas with the guideline, ${ }^{18}$ which may explain non-compliance. Patients assumed to be at higher risk for other reasons than adenoma number may have received earlier surveillance colonoscopy than recommended by the guideline. This latter can also be an explanation why the yield of AA was similar for patients with too early surveillance compared with those having appropriately timed surveillance (7\% and 5\%, respectively). Last year the Dutch guideline has been updated and includes additional adenoma characteristics (http://www.mdl.nl/uploads/240/1308/Richtlijn_Coloscopie

Surveillance_definitief_2013.pdf). Although we combined index colonoscopies within 6 months, some patients still did not have sufficient bowel preparation (165 of those with surveillance), however it turned out not to be a reason for earlier surveillance. Intervals were not different from patients with sufficient bowel preparation (data not shown).

Our findings that surveillance was too frequent in patients whose recommended surveillance intervals were longer (ie, 3 and 6 years) are in line with self-reported surveillance intervals in US and European surveys among gastroenterologists and/or surgeons, ${ }^{16-18} 2022$ and also with the few smaller studies that assessed the appropriate timing of postpolypectomy surveillance colonoscopy in clinical practice. ${ }^{32} 40$ In the latter, $46-54 \%$ of the patients with surveillance received it too early. ${ }^{32}{ }^{40}$ In our study, the corresponding percentage was even higher: $76 \%$ (ie, $48 \%$ of $63 \%$ of the patients with surveillance).

Schoen $e a^{23}$ reported that surveillance colonoscopy was too early in $34 \%$ of patients with a low-risk adenoma profile (patients with one or two non-AAs). The larger proportion of overuse among the low-risk group in our study (48\%) may be explained by the discrepancy in risk stratification between the guidelines in effect: whereas patients with one or two adenomas and high-grade dysplasia, a (tubulo) villous aspect, or a size $\geq 10 \mathrm{~mm}$ are classified as high-risk patients according to the US guideline and advised a 3-year surveillance interval, ${ }^{9}$ the Dutch 2002 guidelines classified these patients as 'low-risk' and recommended a 6-year interval. ${ }^{10}$ Physicians in the Netherlands may have shortened the intervals for these patients, considering them to be at higher risk. ${ }^{18}$ On the other hand, we also found a considerably greater overuse of surveillance among patients with a highrisk adenoma profile (39\% in patients with $\geq$ three adenomas) than Schoen et $\mathrm{l}^{23}$ did (14-20\% patients with $\geq$ three non-AAs or $\geq$ one AA). In the USA, high-risk patients have been recommended a 3-year interval since 1993. As a consequence, US physicians may be more familiar with the 3-year recommendation than the Dutch physicians were in 2002. Generally, the proportion of patients with too early surveillance tends to be higher among low-risk patients than among higher-risk patients, ${ }^{23} 323941$ which may again be inherent to the relatively longer recommended surveillance interval itself or be related to a perceived need for shorter surveillance by patients or their physicians.

An important finding in our study is that an estimated third of patients do not receive surveillance colonoscopy after adenoma detection in community practice. Schoen et $a^{23}$ 

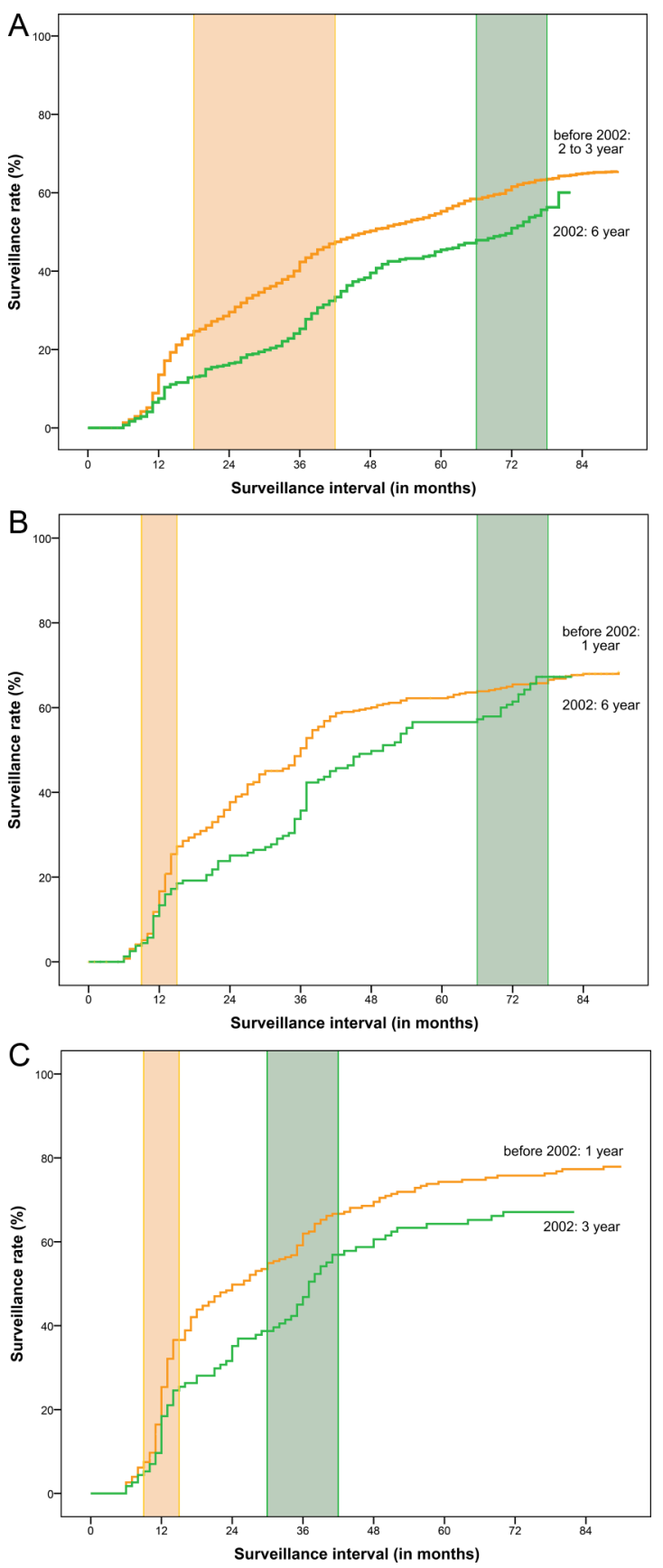

Figure 2 (A) Kaplan-Meier probability curve for surveillance colonoscopy use by month from index colonoscopy for patients with one adenoma, stratified by active guideline. The shaded areas indicate appropriate intervals around $2-3$ years $(<2002, n=1676)$ and 6 years (2002, n=417). (B) Kaplan-Meier probability curve for surveillance colonoscopy use by month from index colonoscopy for patients with two adenomas, stratified by active guideline. The shaded areas indicate appropriate intervals around 1 year $(<2002, n=397)$ and 6 years $(2002$, $n=160$ ). (C) Kaplan-Meier probability curve for surveillance colonoscopy use by month from index colonoscopy for patients with three or more adenomas, stratified by active guideline. The shaded areas indicate appropriate intervals around 1 year $(<2002, n=230)$ and 3 years (2002, n=117).

reported that approximately half of patients had not (yet) received surveillance colonoscopy after 5 years. These data were based on patient questionnaires and lacked actual assessment of hospital records. Cooper et $a l^{42}$ found a similar proportion using Medicare claims data. However, this population only included subjects aged 70 years and above. Furthermore, as this study was based on Medicare claims data, it implied that it used endoscopy billing codes, in particular polypectomy, instead of histological evaluation. As such, there was no verification of adenoma removal, and also lacked information on advanced versus non-advanced histology. Appropriateness of adherence to guidelines could thus not be assessed. Insight into the absence of surveillance is important in the light of the $8 \%$ advanced neoplasia $(1.8 \% \mathrm{CRC}, 6.6 \% \mathrm{AA})$ recurrence rate and $25 \%$ non-AA recurrence rate in patients with delayed surveillance. This shows that the observed delays are long enough for neoplasia to reoccur and/or progress, and corroborates the expectation that there is a loss in effectiveness when patients do not have timely or not at all have surveillance colonoscopies.

Our study is one of the few studies to have assessed the actual use of postpolypectomy surveillance colonoscopy in clinical practice in a multicentre setting; and it is of considerable size. But two limitations are noteworthy. First, we assumed no loss to follow-up. We feel this is a reasonable assumption, because patient deaths were well-reported in hospital databases (the observed death rate closely matched the expected rate based on age and gender of the population, data not shown) and we did not find correspondence in medical records on colonoscopies performed elsewhere. Finally, the close link between patient, referring family physician, and hospital in the Netherlands induce that the vast majority of patients in the Netherlands regularly attend the same hospital for surveillance and other purposes. Most importantly, we found our results to be robust for this assumption: even if all patients without surveillance would have died or had their surveillance colonoscopy in another hospital with a similar timing as observed for the other patients, still only $32 \%(21 \% / 66 \%)$ would have received appropriate surveillance.

Second, because of time constraints we collected information on index adenoma number in a random sample of 40\% (433/1093) of the patients without surveillance colonoscopy after adenoma detection. We assume that this sample is representative. We statistically imputed adenoma number for 660 patients. We expect any bias due to misclassification of patients according to number of adenomas (one, two or three+ adenomas) as a result of imputation to be very small, and that it will not have affected adherence rates.

Our results show that postpolypectomy surveillance guidelines are not being applied appropriately-a much larger proportion than one would expect deviates from the recommendations. Some non-compliance, especially delayed or absent surveillance, should be expected for good reasons, notably comorbidity issues. As far as we know there is no literature on comorbidity rates in patients with adenoma, but it is unlikely that the presence of comorbidity fully explains the observed lack of surveillance in our study. Patients who receive adenoma-surveillance too early represent unnecessary endoscopic procedures, harms and costs. As the implementation of mass screening for CRC is expected to (further) increase the demand for colonoscopies considerably, it will become even more important to avoid unnecessary use of resources, especially for low-risk patients. On the other side of the spectrum of non-adherence, delayed or absent surveillance represents loss of health benefits.

Which interventions could improve adherence to surveillance guidelines? Several interventions have been previously suggested. One was to update the Dutch 2002 postpolypectomy surveillance guideline towards less discrepancy with the endoscopist's judgment, and thereby improving physicians' compliance. Other suggestions include an active approach policy directed towards patients and general practitioners to invite patients for a surveillance colonoscopy, ${ }^{19} 43$ to disseminate summarised guidelines 
Table 3 Timing of surveillance colonoscopy relative to recommended intervals according to guideline in effect (by period) and adenoma patient group, Kaplan-Meier analysis

\begin{tabular}{|c|c|c|c|c|c|}
\hline $\begin{array}{l}\text { Period of index } \\
\text { colonoscopy }\end{array}$ & $\begin{array}{l}\text { Recommended } \\
\text { interval (year) }\end{array}$ & Too early (\%) & Appropriate* (\%) & $\begin{array}{l}\text { Delayed or } \\
\text { no surveillance (\%) }\end{array}$ & $\begin{array}{l}\text { No } \\
\text { surveillancet (\%) }\end{array}$ \\
\hline \multicolumn{6}{|l|}{ June 1998-2001 } \\
\hline 1 adenoma $(n=1676)$ & $2-3$ & 24 & 24 & 53 & 35 \\
\hline 2 adenomas $(n=397)$ & 1 & 4 & 23 & 73 & 32 \\
\hline $3+$ adenomas $(n=230)$ & 1 & 6 & 30 & 63 & 22 \\
\hline Overall $(n=2303)$ & & 19 & 24 & 57 & 33 \\
\hline \multicolumn{6}{|l|}{ In 2002} \\
\hline 1 adenoma $(n=417)$ & 6 & 47 & 9 & 44 & 40 \\
\hline 2 adenomas $(n=160)$ & 6 & 57 & 11 & 33 & 33 \\
\hline $3+$ adenomas $(n=117)$ & 3 & 39 & 18 & 43 & 33 \\
\hline Overall $(n=694)$ & & 48 & 11 & 41 & 37 \\
\hline Overall, all patients $(n=2997)$ & & 25 & 21 & 53 & 34 \\
\hline
\end{tabular}

Due to rounding row percentages may not add up to $100 \%$.

${ }^{*}$ Appropriate interval, before 2002: 1-year plus or minus 3 months, 2-3 years plus or minus 6 months; and in 2002: 3- or 6-years plus or minus 6 months.

tby the end of the study (1 December 2008) or within 90 months, whichever came first.

among professionals through the distribution of wallet-sized cards (which nowadays can also be applications for mobile devices), to place guideline charts near workstations, to reinforce guidelines in regular continuous quality-improvement meetings 44 and to supervise application of guidelines by a nurse coordinator. $^{45}{ }^{46}$ It is also necessary to increase patients' awareness in terms of their adenoma findings and the need for surveillance, including recommended surveillance interval. ${ }^{47}$ Implementation studies are required to determine which of the interventions work best. Monitoring postpolypectomy surveillance intervals combined with efforts to encourage timely adherence should be a mainstay in continuous quality improvement.

In conclusion, the vast majority of patients with adenoma in community-based clinical practice (76-89\%) did not receive surveillance timed according to Dutch postpolypectomy surveillance guidelines. The poor penetration of the 2002 guideline within 1 year following the implementation, illustrates the importance of convincing evidence to support endorsement of new guidelines by community practice. Our results suggest that there is considerable room for improving the effectiveness and efficiency of surveillance practice, because too early surveillance poses a considerable burden on available resources while delayed surveillance is associated with an increased rate of AA and especially CRC. Since adherence to guidelines is mandatory for the effectiveness and cost-effectiveness of CRC prevention (including CRC screening programs), measures should be taken to improve adherence. Implementation studies are needed to determine which of the potential interventions work best.

\section{Author affiliations}

${ }^{1}$ Department of Public Health, Erasmus MC University Medical Centre, Rotterdam, the Netherlands

${ }^{2}$ Department of Gastroenterology and Hepatology, Academic Medical Centre, University of Amsterdam, Amsterdam, the Netherlands

${ }^{3}$ Department of Gastroenterology and Hepatology, Erasmus MC University Medical Centre, Rotterdam, the Netherlands

${ }^{4}$ Department of Gastroenterology, Albert Schweitzer hospital, Dordrecht, the Netherlands

${ }^{5}$ Department of Gastroenterology and Hepatology, Deventer Hospital, Deventer, the Netherlands

${ }^{6}$ Department of Gastroenterology and Hepatology, Isala Clinics, Zwolle, the Netherlands

Table 4 Yield of advanced adenoma (AA) at surveillance endoscopy according to number of adenomas at index colonoscopy and timing of surveillance according to the guidelines $(n=1904)$

\begin{tabular}{|c|c|c|c|c|c|}
\hline \multirow{2}{*}{$\begin{array}{l}\text { Period of index } \\
\text { colonoscopy }\end{array}$} & \multirow{2}{*}{$\begin{array}{l}\text { Recommended } \\
\text { interval (year) }\end{array}$} & \multicolumn{4}{|l|}{ AA (n/n total) } \\
\hline & & Too early & Appropriate† & Delayed & Total \\
\hline \multicolumn{6}{|l|}{ June 1998-2001 } \\
\hline 1 adenoma & $2-3$ & $3 \%(12 / 389)$ & $3 \%(13 / 384)$ & $7 \%(21 / 298)^{*}$ & $4 \%(46 / 1071)$ \\
\hline 2 adenomas & 1 & $6 \%(1 / 16)$ & $3 \%(3 / 90)$ & $6 \%(10 / 159)$ & $5 \%(14 / 265)$ \\
\hline $3+$ adenomas & 1 & $7 \%(1 / 14)$ & $9 \%(6 / 68)$ & $17 \%(15 / 89)$ & $13 \%(22 / 171)$ \\
\hline Overall & & $3 \%(14 / 419)$ & $4 \%(22 / 542)$ & $8 \%(46 / 546)^{\star *}$ & $5 \%(82 / 1507)$ \\
\hline \multicolumn{6}{|l|}{ In 2002} \\
\hline 1 adenoma & 6 & $5 \%(9 / 193)$ & $7 \%(2 / 28)$ & $0 \%(0 / 3)$ & $5 \%(11 / 224)$ \\
\hline 2 adenomas & 6 & $9 \%(8 / 86)$ & $8 \%(1 / 12)$ & - & $9 \%(9 / 98)$ \\
\hline $3+$ adenomas & 3 & $16 \%(7 / 44)$ & $0 \%(0 / 20)$ & $9 \%(1 / 11)$ & $11 \%(8 / 75)$ \\
\hline Overall & & $7 \%(24 / 323)$ & $5 \%(3 / 60)$ & $7 \%(1 / 14)$ & $7 \%(28 / 397)$ \\
\hline Total & & $5 \%(38 / 742)$ & $4 \%(25 / 602)$ & $8 \%(47 / 560)^{* *}$ & $6 \%(110 / 1904)$ \\
\hline
\end{tabular}


${ }^{7}$ Department of Gastroenterology and Hepatology, Medical Centre Leeuwarden, Leeuwarden, the Netherlands

${ }^{8}$ Department of Gastroenterology and Hepatology, Orbis Medical Centre, Sittard, the Netherlands

${ }^{9}$ Department of Gastroenterology and Hepatology, Reinier de Graaf Hospital, Delft, the Netherlands

${ }^{10}$ Department of Gastroenterology and Hepatology, St. Antonius Hospital, Nieuwegein, the Netherlands

${ }^{11}$ Department of Gastroenterology, University Medical Centre Groningen, University of Groningen, Groningen, the Netherlands

${ }^{12}$ Department of Internal Medicine, Erasmus MC University Medical Centre, Rotterdam, the Netherlands

Acknowledgements The authors thank the staff of the gastroenterology and pathology departments at the following hospitals for their participation in this study: Academic Medical Centre, Amsterdam; Albert Schweitzer Hospital, Dordrecht; Deventer Hospital, Deventer; Erasmus MC, University Medical Centre, Rotterdam; Isala Clinics, Zwolle; Medical Centre Leeuwarden, Leeuwarden; Orbis Medical Centre, Sittard; Reinier de Graaf Hospital, Delft; St. Antonius Hospital, Nieuwegein; and University Medical Centre Groningen, Groningen. The authors thank Mariel Casparie from the Pathologisch Anatomisch Landelijk Geautomatiseerd Archief (PALGA) institute for identifying the patients with adenoma for the participating hospital-pathology laboratories; Katharina Biermann for her help regarding pathological issues (PALGA query and during data collection); Anke Enneman, Janine de Zeeuw, Isabel Siemelink, Irene van Sloten, Simone van Kessel, Emma Steenbergen and Judith van den Broek for their assistance in data collection; and Frank Santegoets for his cooperation in database development and data management.

Contributors IL-V, EJK and MvB were responsible for the study design, grant application and study supervision. E-MBvH, IL-V, EJK and MvB drafted the manuscript. All authors have contributed to the study concept and design; interpretation of the data; critical revision of the manuscript for important intellectual content. In addition E-MBvH and IL-V were responsible for the statistical analysis. All authors read and approved the final manuscript.

Funding This study was funded by ZonMw (the Netherlands Organisation for Health Research and Development), project number 170882801.

Competing interests CJMB is a member of a MSD medical advisory board. Ethics approval Institutional Review Board of Erasmus MC University Medical Centre.

Provenance and peer review Not commissioned; externally peer reviewed.

Open Access This is an Open Access article distributed in accordance with the Creative Commons Attribution Non Commercial (CC BY-NC 3.0) license, which permits others to distribute, remix, adapt, build upon this work non-commercially, and license their derivative works on different terms, provided the original work is properly cited and the use is non-commercial. See: http://creativecommons.org/ licenses/by-nc/3.0/

\section{REFERENCES}

1 Ferlay J, Steliarova-Foucher E, Lortet-Tieulent J, et al. Cancer incidence and mortality patterns in Europe: estimates for 40 countries in 2012. Eur J Cancer 2013;49:1374-403.

2 Siegel R, Ma J, Zou Z, et al. Cancer statistics, 2014. CA Cancer J Clin 2014;64:9-29.

3 Cottet $\mathrm{V}$, Jooste $\mathrm{V}$, Fournel I, et al. Long-term risk of colorectal cancer after adenoma removal: a population-based cohort study. Gut 2012;61:1180-6.

4 Leung $\mathrm{K}$, Pinsky $\mathrm{P}$, Laiyemo $\mathrm{AO}$, et al. Ongoing colorectal cancer risk despite surveillance colonoscopy: the Polyp Prevention Trial Continued Follow-up Study. Gastrointest Endosc 2010;71:111-17.

5 Martinez ME, Baron JA, Lieberman DA, et al. A pooled analysis of advanced colorectal neoplasia diagnoses after colonoscopic polypectomy. Gastroenterology 2009:136:832-41.

6 Winawer SJ, Zauber AG, Ho MN, et al. Prevention of colorectal cancer by colonoscopic polypectomy. The National Polyp Study Workgroup. N Engl J Med 1993;329:1977-81

7 Atkin WS, Valori R, Kuipers EJ. Colonoscopic surveillance following adenoma removal. In: Segnan N, Patnick J, von Karsa L. eds. European guidelines for quality assurance in colorectal cancer screening and diagnosis. Luxembourg: European Commission. Publication Office of the European Union, 2010:273-98.

8 Cairns SR, Scholefield JH, Steele RJ, et al. Guidelines for colorectal cancer screening and surveillance in moderate and high risk groups (update from 2002). Gut 2010;59:666-89

9 Lieberman DA, Rex DK, Winawer SJ, et al. Guidelines for colonoscopy surveillance after screening and polypectomy: a consensus update by the US Multi-Society Task Force on Colorectal Cancer. Gastroenterology 2012;143:844-57.

10 Nagengast FM, Kaandorp CJ. [Revised CBO guideline 'Follow-up after polypectomy']. Ned Tijdschr Geneeskd 2001;145:2022-5.

11 Lieberman DA, De Garmo PL, Fleischer DE, et al. Patterns of endoscopy use in the United States. Gastroenterology 2000;118:619-24.
12 Lieberman DA, Holub J, Eisen G, et al. Utilization of colonoscopy in the United States: results from a national consortium. Gastrointest Endosc 2005;62:875-83.

13 Gezondheidsraad (The Health Council of the Netherlands). Bevolkingsonderzoek naar darmkanker. Den Haag: Gezondheidsraad, 2009: publicationnumber 13.

14 Terhaar Sive Droste IS, Craanen ME, van der Hulst RW, et al. Colonoscopic yield of colorectal neoplasia in daily clinical practice. World I Gastroenterol 2009;15:1085-92.

15 Goodwin JS, Singh A, Reddy N, et al. Overuse of screening colonoscopy in the Medicare population. Arch Intern Med 2011;171:1335-43.

16 Huppertz J, Coriat R, Leblanc S, et al. Application of ANAES guidelines for colonoscopy in France: a practical survey. Gastroenterol Clin Biol 2010;34: 541-8.

17 Krist AH, Jones RM, Woolf SH, et al. Timing of repeat colonoscopy: disparity between guidelines and endoscopists' recommendation. Am J Prev Med 2007;33:471-8.

18 Mulder SA, Ouwendijk RJ, van Leerdam ME, et al. A nationwide survey evaluating adherence to guidelines for follow-up after polypectomy or treatment for colorectal cancer. J Clin Gastroenterol 2008;42:487-92.

19 Mulder SA, Van Leerdam ME, Ouwendijk RJ, et al. Attendance at surveillance endoscopy of patients with adenoma or colorectal cancer. Scand I Gastroenterol 2007:42:66-71.

20 Mysliwiec PA, Brown ML, Klabunde CN, et al. Are physicians doing too much colonoscopy? A national survey of colorectal surveillance after polypectomy. Ann Intern Med 2004;141:264-71.

21 O'Connor A, Keane RA, Egan B, et al. Adherence to colorectal polyp surveillance guidelines: is there a 'scope' to increase the opportunities for screening? Eur J Cancer Prev 2011;20:40-5.

22 Saini SD, Nayak RS, Kuhn L, et al. Why don't gastroenterologists follow colon polyp surveillance guidelines?: results of a national survey. J Clin Gastroenterol 2009:43:554-8

23 Schoen RE, Pinsky PF, Weissfeld IL, et al. Utilization of surveillance colonoscopy in community practice. Gastroenterology 2010;138:73-81.

24 van Turenhout ST, Terhaar Sive Droste JS, Meijer GA, et al. Anticipating implementation of colorectal cancer screening in the Netherlands: a nationwide survey on endoscopic supply and demand. BMC Cancer 2012;12:46.

25 National Institute for Public Health and the Environment (RIVM). [Bevolkingsonderzoek darmkanker vanaf 2013, stand van zaken invoering, maart 2012]. Bilthoven: Ministry of Health, Welfare and Sport: RIVM, 2012.

26 van Hees F, Lansdorp-Vogelaar I, van Ballegooijen M. [De benodigde extra capaciteit in de zorg, de kosten en de voorkomen sterfte aan dikkedarmkanker na introductie van een bevolkingsonderzoek naar dikkedarmkanker in Nederland]. Rotterdam: Erasmus MC University Medical Centre, 2011.

27 Chivers K, Basnyat P, Taffinder N. The impact of national guidelines on the waiting list for colonoscopy: a quantitative clinical audit. Colorectal Dis 2010;12:632-9.

28 Leddin D, Bridges RJ, Morgan DG, et al. Survey of access to gastroenterology in Canada: the SAGE wait times program. Can I Gastroenterol 2010;24:20-5.

29 Price J, Campbell C, Sells J, et al. Impact of UK Colorectal Cancer Screening Pilot on hospital diagnostic services. J Public Health (Oxf) 2005;27:246-53.

30 Yeoman A, Parry S. A survey of colonoscopy capacity in New Zealand's public hospitals. NZ Med J 2007;120:U2632.

31 van Kooten $\mathrm{H}$, de Jonge $\mathrm{V}$, Schreuders $\mathrm{E}$, et al. Awareness of postpolypectomy surveillance guidelines: a nationwide survey of colonoscopists in Canada. Can J Gastroenterol 2012:26:79-84.

32 Schreuders E, Sint Nicolaas J, de Jonge V, et al. The appropriateness of surveillance colonoscopy intervals after polypectomy. Can J Gastroenterol 2013;27:33-8.

33 Arguello L, Pertejo V, Ponce $M$, et al. The appropriateness of colonoscopies at a teaching hospital: magnitude, associated factors, and comparison of EPAGE and EPAGE-II criteria. Gastrointest Endosc 2012;75:138-45.

34 Casparie M, Tiebosch AT, Burger G, et al. Pathology databanking and biobanking in the Netherlands, a central role for PALGA, the nationwide histopathology and cytopathology data network and archive. Cell Oncol 2007;29:19-24.

35 Nagengast FM, Snel P. [Herziening Consensus Follow-up na poliepectomie (namens de Werkgroep Herziening Consensus Follow-up na poliepectomie)]. Ned Tijdschr Geneeskd 1998;142:1353.

36 Snel P, de Wolf AN. [Consensus follow-up study after polypectomy]. Ned Tijdschr Geneeskd 1988:132:489-91.

37 Dutch Institute for Healthcare Improvement. [Herziene richtlijn: Follow-up na poliepectomie]. Utrecht: Kwaliteitsinstituut voor de Gezondheidszorg CBO, 2002.

38 van Buuren S, Boshuizen HC, Knook DL. Multiple imputation of missing blood pressure covariates in survival analysis. Stat Med 1999;18:681-94.

39 Pickard M, Dewar EP, Kapadia RC, et al. Follow up of patients with colorectal polyps: are the BSG guidelines being adhered to? Colorectal Dis 2007:9:203-6.

40 Radaelli F, Paggi S, Bortoli A, et al. Overutilization of post-polypectomy surveillance colonoscopy in clinical practice: a prospective, multicentre study. Dig Liver Dis 2012;44:748-53

41 Ransohoff DF, Yankaskas B, Gizlice Z, et al. Recommendations for post-polypectomy surveillance in community practice. Dig Dis Sci 2011;56:2623-30. 


\section{Colon}

42 Cooper GS, Kou TD, Barnholtz Sloan JS, et al. Use of colonoscopy for polyp surveillance in Medicare beneficiaries. Cancer 2013;119:1800-7.

43 Leffler DA, Neeman N, Rabb JM, et al. An alerting system improves adherence to follow-up recommendations from colonoscopy examinations. Gastroenterology 2011;140:1166-73.

44 Sanaka MR, Super DM, Feldman ES, et al. Improving compliance with postpolypectomy surveillance guidelines: an interventional study using a continuous quality improvement initiative. Gastrointest Endosc 2006;63: 97-103.
45 Bampton PA, Sandford JJ, Young GP. Applying evidence-based guidelines improves use of colonoscopy resources in patients with a moderate risk of colorectal neoplasia. Med J Aust 2002;176:155-7.

46 Bampton PA, Sandford JJ, Young GP. Achieving long-term compliance with colonoscopic surveillance guidelines for patients at increased risk of colorectal cancer in Australia. Int J Clin Pract 2007;61:510-3.

47 Sint Nicolaas J, de Jonge V, Cahen DL, et al. Awareness of surveillance recommendations among patients with colorectal adenomas. Clin Gastroenterol Hepatol 2012;10:405-11. 